\title{
A randomized crossover study comparing tafluprost $0.005 \%$ with travoprost $0.004 \%$ in patients with normal-tension glaucoma
}

This article was published in the following Dove Press journal:

Clinical Ophthalmology

24 September 2012

Number of times this article has been viewed

\author{
Takanori Mizoguchi' \\ Mineo Ozaki² \\ Kazuhiko Unoki ${ }^{3}$ \\ Yoshinori Dake ${ }^{4}$ \\ Takahiko Eto ${ }^{5}$ \\ Miki Arai ${ }^{6}$ \\ 'Mizoguchi Eye Clinic, ${ }^{2}$ Ozaki Eye \\ Clinic, Miyazaki, Japan; ${ }^{3}$ Unoki Eye \\ Clinic, Kagoshima, Japan; ${ }^{4}$ Dake Eye \\ Clinic, Nagasaki, Japan; ${ }^{5}$ Eto Eye Clinic, \\ Oita, Japan; ${ }^{6}$ Arai Eye Clinic, Fukuoka, \\ Japan
}

Purpose: We compared the intraocular pressure (IOP)-lowering effect of tafluprost $0.0015 \%$ once daily with travoprost $0.004 \%$ once daily in Japanese patients with normal-tension glaucoma (NTG).

Methods: One hundred sixteen patients with NTG were randomized to use tafluprost $0.0015 \%$ or travoprost $0.004 \%$ once daily for 12 weeks, followed by a washout period of 4 weeks between switching medications. IOP was measured at baseline and 4, 8, and 12 weeks of each treatment period.

Results: Ninety patients completed both treatment periods and had IOP data available for evaluation. In both groups, a significant decrease in IOP was observed for all measurement points compared with baseline values $(P<0.0001)$. There was no significant difference in IOP at each time point between the two groups. Both drugs were effective (defined as more than $10 \%$ IOP reduction) in 39 (43\%) of 90 patients; only tafluprost was effective in 26 (29\%) patients, and only travoprost was effective in $17(19 \%)$ patients. Eight $(9 \%)$ patients were nonresponders to both drugs.

Conclusions: Tafluprost and travoprost were equally effective in lowering IOP in patients with normal-tension glaucoma. However, patients with normal-tension glaucoma may vary in response to each medication.

Keywords: intraocular pressure reduction, normal-tension glaucoma, responder, tafluprost $0.005 \%$, travoprost $0.004 \%$

\section{Introduction}

Elevated intraocular pressure (IOP) is a risk factor for the development and progression of glaucoma. ${ }^{1,2}$ However, in cases of normal-tension glaucoma (NTG), glaucomatous damage may advance gradually even if IOP remains within the normal range. ${ }^{1,2}$ However, IOP remains part of the pathogenesis of NTG, and lowering IOP is effective for reducing the progression of glaucomatous damage.

A survey of the prevalence of glaucoma in Japanese population was conducted from 2000 to 2001 in Tajimi city. The report revealed that the prevalence of NTG was $3.6 \%$, which is much higher than the prevalence of primary open angle glaucoma with high IOP levels ( $>21 \mathrm{mmHg}$ ) at $0.3 \%$. IOP of $92 \%$ of patients with primary open angle glaucoma was $21 \mathrm{mmHg}$ or less without glaucoma medications and average IOP in primary open angle glaucoma patients was $15.2-15.4 \mathrm{mmHg}$, which was within the normal IOP range in the Japanese population. ${ }^{3}$ However, IOP in these patients was significantly higher than that of nonglaucomatous subjects. Therefore, it is very important to reduce IOP in patients with NTG in Japan.
Correspondence: Takanori Mizoguchi Mizoguchi Eye Clinic, 6-13 Tawaramachi, Sasebo, Nagasaki, Japan 857-0016

$\mathrm{Tel}+81956256040$

Fax +81956256040

Email t-mizo@siren.ocn.ne.jp 
Recently, several prostaglandin analogues (PGs) have been developed as IOP-lowering agents. They play important roles in the management of glaucoma because of their potent IOP-lowering activity. Studies have demonstrated the effectiveness of PGs in lowering IOP in patients with NTG. ${ }^{4-14}$ However, it has been reported that the IOP-lowering effect may differ among different PGs, and the presence of responders and nonresponders to the same type of drug has been reported. ${ }^{15-18}$ Thus, many questions remain regarding the effects of PGs in the management of NTG.

In this study, we conducted a randomized crossover study to compare the IOP-lowering effect of tafluprost and travoprost in patients with NTG to investigate the percentage and characteristics of responders and nonresponders to these two drugs.

\section{Subjects and methods}

This was a prospective, randomized, open-label, multicenter crossover study carried out at six centers during the period from February 1, 2009 to April 30, 2010. The study followed the tenets of the Declaration of Helsinki and received approval from the ethics committee of each participating facility. Written informed consent was obtained from each patient before the start of the study. This study was registered at University hospital Medical Information Network (UMIN): 000001829.

Patients with NTG satisfying all of the following inclusion criteria were eligible for the study: (1) age over 20 years, (2) corrected visual acuity of over 0.1 , (3) no history of previous treatment of glaucoma or completion of at least a 4-week washout period after previous therapy for glaucoma, (4) reproducible visual field assessment with a fixation loss of less than $20 \%$ and false-positive and false-negative rates of less than $30 \%$ if possible with Swedish interactive thresholding algorithm (SITA) standard 24-2 measured with a Humphrey's perimeter (model 750; Humphrey Instruments, San Leandro, CA). The exclusion criteria were: (1) patients with exfoliation syndrome, (2) patients with diabetic retinopathy (Fukuda's class AII or severer), ${ }^{19}$ (3) patients with visual field defects with mean deviation $\leq-15 \mathrm{~dB}$, (4) patients with spherical $\leq-6 \mathrm{D}$ (diopter), (5) patients with a history of ocular trauma, ocular inflammatory disease, intraocular surgery, or laser trabeculoplasty, (6) patients with conjunctivitis, dry eye, or periocular cutaneous diseases possibly affecting the results of the investigation, (7) currently pregnant or nursing women, or women considering pregnancy, (8) patients with a history of noncompliance, (9) patients who participated in another therapeutic drug study within one month, and (10) a history of cerebrovascular and hepatic disease.

The diagnosis of NTG was made if all of the following criteria were satisfied: (1) presence of glaucomatous optic disc neuropathy (a cup/disc ratio of $\geq 0.7$, or the presence of notching) accompanied by corresponding visual field defects, (2) a threshold examination of SITA 24-2 showing a glaucoma hemifield test (GHT) “outside normal limits," and a cluster of three contiguous points on the pattern deviation plot depressed at $P<5 \%$ level (occurring in age-matched normal subjects) not crossing the horizontal meridian were compatible with glaucoma, (3) assessed as an open angle on gonioscopy, and (4) IOP $<21 \mathrm{mmHg}$ in at least three prestudy visits for untreated patients, or IOP $<21 \mathrm{mmHg}$ at baseline visits after washing out of the previous therapy.

In cases of bilateral NTG, the eye with the higher IOP at the end of the washout period was adopted for evaluation of the test drug. In cases of bilateral NTG with equal IOP, the right eye was tested. The patients enrolled in the study were divided at random into two groups, a group treated with tafluprost ophthalmic solution $0.0015 \%$ (TAPROS $^{\circledR}$, Santen Pharmaceutical Co, Ltd, Osaka, Japan) and a group treated with travoprost ophthalmic solution $0.004 \%$ (Travatan ${ }^{\circledR} Z$; Alcon Laboratories Inc, Fort Worth, TX). The IOP at the start of the study served as the baseline IOP. IOP measurements were carried out at 4,8 , and 12 weeks. Treatment with each drug was suspended for 4 weeks (washout period), and the IOP at the end of the washout period served as the baseline IOP for the second treatment period. During the second treatment period, drugs were administered in a crossover fashion to the two groups, and measurements and assessments were identical to those conducted during the first treatment period.

A-scan biometry (US-800; Nidek Co, Ltd, Tokyo, Japan) and pachymeter (SP-2000; Topcon, Tokyo, Japan) were used to measure axial length and central corneal thickness, respectively. Three sessions of IOP were measured at 9:00 am using a Goldman applanation tonometer (Haag-Streit, Bern, Switzerland). If the difference in the IOP between any two of the three sessions of measurement was greater than $3 \mathrm{mmHg}$, the median value was used; if the difference was less than $3 \mathrm{mmHg}$, the mean value was used.

\section{Statistical analysis}

Prior to the study, it was estimated that 90 patients should be randomized among both treatment groups in order to detect a difference of $1.2 \mathrm{mmHg}$ between groups at a significance level of 0.05 , a power of $80 \%$, and given a standard deviation 
of $2.0 \mathrm{mmHg}$ for IOP change from baseline. To allow for withdrawal, over 100 patients were enrolled in this study. Baseline and post-treatment values were compared using one-way repeated-measures analysis of variance test for each treatment group. The difference in IOP between the two groups was assessed using unpaired $t$-test. Pearson's $X^{2}$-square test was used for inter-group comparison of the percentage of patients in whom each goal of IOP reduction was achieved. Correlation between baseline IOP and percent IOP reduction was analyzed using polynominal regression analysis. $P<0.05$ (two-tailed) was regarded as statistically significant. Statistical analysis was performed using the Statistical Analysis System (SAS) software, version 8 (SAS Institute Inc, Japan).

\section{Results}

A total of 116 patients (116 test eyes) were enrolled in this study. Ten patients dropped out of the study prematurely due to change of residence and discontinued their visits. Three patients treated with travoprost were discontinued because they developed conjunctival hyperemia and ocular irritation. Two patients were excluded from analysis due to failure to comply with dosing instructions. One patient was excluded because he underwent cataract surgery. After excluding these 16 cases, 90 patients treated with tafluprost and travoprost in a crossover fashion were included in the final analysis. During Treatment Period I, 48 patients were treated with tafluprost and 42 patients were treated with travoprost.

Demographic features are summarized in Table 1. All patients were Japanese. The mean age was $69.4 \pm 8.8$ years

\begin{tabular}{ll} 
Table I Patient characteristics & \\
\hline Characteristics $(\mathbf{n}=\mathbf{9 0})$ & \\
\hline Age $(\mathbf{y})$ & $69.4 \pm 8.8$ \\
Gender & 23 \\
Male & 67 \\
Female & $15.5 \pm 2.3$ \\
Washout IOP $(\mathrm{mmHg})$ & \\
Previous therapy & 29 \\
New patients & 53 \\
Latanoprost & 3 \\
Tafluprost & 2 \\
Travoprost & 1 \\
LTFC & 2 \\
Timolol & $529.1 \pm 35.9$ \\
Central corneal thickness $(\mu \mathrm{m})$ & $23.54 \pm 1.08$ \\
Axial length $(\mathrm{mm})$ & $-0.76 \pm 1.89$ \\
Spherical equivalent (diopter) & $-3.84 \pm 3.35$ \\
Mean deviation $(\mathrm{dB})$ &
\end{tabular}

Abbreviations: IOP, intraocular pressure; LTFC, Latanoprost $0.005 \%$ and timolo $0.5 \%$ fixed combination. (range: 50-86 years). There were 23 males and 67 females. Table 2 shows the IOP and the percent IOP reduction from baseline at each point of evaluation. There was no significant difference in the baseline IOP between the tafluprost and the travoprost groups $(P=0.811)$. In both groups, significant decreases in IOP were observed at each time-point of measurement compared with baseline $(P<0.0001)$. However, there were no significant differences in the IOP and the percent IOP reduction at each time points between the two groups.

The IOP and percent IOP reduction at each time-point of measurement during tafluprost or travoprost treatment were compared between patients with a baseline IOP of $15 \mathrm{mmHg}$ or higher (the highteens group) and those with the baseline IOP of less than $15 \mathrm{mmHg}$ (the lowteens group) (Table 3 ). In the high-teens group and the low-teens group, a significant decrease of the IOP was observed at each time point of measurement compared with the baseline in the tafluprost and the travoprost groups $(P<0.0001)$; however, there was no significant difference in the IOP and the percent IOP reduction from baseline IOP at any time-point between tafluprost and travoprost group.

IOP response rates are shown in Table 4. In total, there was no significant difference between the two groups. In the high-teens group, there was no significant difference between the two groups $(P=0.277)$. However, in the low-teens group, an IOP response rate greater than $10 \%$ from baseline was achieved by $22(66.7 \%)$ patients and $19(52.8 \%)$ patients in the tafluprost group and travoprost group, respectively. There was a significant difference between the two groups $(P=0.045)$.

Figure 1A shows the relationship between percent IOP reduction of tafluprost and that of travoprost in individual patients. When cases showing a $10 \%$ or more IOP reduction at 12 weeks from the baseline IOP were defined as a responder, 39 (43\%) of the 90 patients were responders to both drugs, 26 patients $(29 \%)$ were responders only to tafluprost, 17 patients (19\%) were responders only to travoprost, and 8 patients ( $9 \%$ ) were nonresponders to both drugs. Figure $1 \mathrm{~B}$ shows the correlation between baseline IOP and percent IOP reduction in the tafluprost group and the travoprost group. In the tafluprost group, baseline IOP was not significantly correlated with percent IOP reduction $(P=0.381, \mathrm{r}=0.270)$. In the travoprost group, however, elevation of baseline IOP was associated with a significant decrease in percent reduction of IOP $(P=0.0068, \mathrm{r}=0.388)$.

\section{Discussion}

Numerous reports have demonstrated the effectiveness of PGs in the treatment of NTG. ${ }^{3-14}$ According to a recent meta- 
Table 2 The mean intraocular pressure (IOP) at each time point and percent reduction (\%) in mean IOP from baseline IOP

\begin{tabular}{|c|c|c|c|}
\hline \multirow[t]{2}{*}{ Time } & \multicolumn{2}{|l|}{ Mean IOP (mmHg) } & \multirow{2}{*}{$\begin{array}{l}P \text { value } \\
\text { (unpaired } t \text {-test) }\end{array}$} \\
\hline & Tafluprost $(n=90)$ & Travoprost $(n=90)$ & \\
\hline Baseline & $15.5 \pm 2.3$ & $15.4 \pm 2.2$ & 0.811 \\
\hline 4 weeks & $13.1 \pm 2.4^{* *}$ & $13.0 \pm 2.2 * *$ & 0.686 \\
\hline 8 weeks & $13.2 \pm 2.3 * *$ & $12.9 \pm 2.0 * *$ & 0.319 \\
\hline 12 weeks & $13.2 \pm 2.3^{* *}$ & $13.2 \pm 2.3^{* *}$ & 0.968 \\
\hline \multicolumn{4}{|c|}{ Percent reduction in mean IOP from baseline (\%) } \\
\hline 4 weeks & $14.0 \pm 12.7$ & $15.3 \pm 11.5$ & 0.834 \\
\hline 8 weeks & $14.3 \pm 12.4$ & $16.2 \pm 10.2$ & 0.272 \\
\hline 12 weeks & $14.3 \pm 12.2$ & $14.0 \pm 11.2$ & 0.824 \\
\hline
\end{tabular}

Notes: $* * P<0.001$ vs Baseline, One-way repeated-measures analysis of variance.

analysis from NTG cases, treatment with latanoprost resulted in a peak percent IOP reduction of $17 \%-24 \%$ (mean: $20 \%$ ) relative to baseline IOP, and treatment with bimatoprost also yielded favorable results, ie, a peak percent IOP reduction of $16 \%-25 \%$ (mean: $21 \%$ ) was reported. ${ }^{20}$ In regard to the IOP-lowering effect of tafluprost and travoprost in patients with NTG, several reports showed favorable results, with a reduction in the IOP by $16 \%-25 \% .{ }^{11-14}$ These previous results suggest that favorable IOP-lowering effects may also be expected of PGs in cases of NTG. Our results show that percent IOP reduction at the last point of evaluation was $14.3 \%$ in the tafluprost group and $14.0 \%$ in the travoprost group and the percentage of the patients in whom a $20 \%$ or more IOP reduction achieved was $36.7 \%$ in the tafluprost group and $35.3 \%$ in the travoprost group. These two drugs are effective for lowering IOP in Japanese patients with NTG, without any significant difference in efficacy between the two drugs. The study also showed that the correlation between baseline IOP and percent IOP reduction differs between drugs. The IOP lowering effect of tafluprost was not correlated with baseline IOP. This result suggests that tafluprost is effective in any baseline IOP. Interestingly, tafluprost and travoprost were effective for lowering IOP even in the low-teens group. It has been reported that the IOP-lowering effect may differ among different PGs; the presence of both responders and nonresponders to the same type of drug has been reported. Camras and Hedman ${ }^{17}$ and Rossetti et al ${ }^{18}$ reported that $4.1 \%$ of subjects were nonresponders, which were defined as patients who did not experience a decrease in IOP of at least $15 \%$ from the baseline IOP. However, no studies have examined the response of one PG nonresponder to other PGs. When patients in whom $10 \%$ or more reduction of the IOP from the baseline were defined as responders, $43 \%$ of all patients were rated as responders to both tafluprost and travoprost. However, approximately $19 \%$ and $29 \%$ of patients responded only to travoprost or to tafluprost, respectively (Figure 1A). A more surprising finding was that there were two patients $(2 \%)$ whose IOP reduction was $30 \%$ or more in tafluprost and $10 \%$ or less in travoprost. These results indicate that there are some cases whose susceptibility differs

Table 3 The mean intraocular pressure (IOP) and percent reduction (\%) from the baseline IOP at each time point in highteens group and lowteens group among study subjects who completed the trial

\begin{tabular}{|c|c|c|c|c|}
\hline \multirow[t]{3}{*}{ Time } & \multicolumn{2}{|c|}{ Tafluprost (highteens group: $n=57$ ) } & \multicolumn{2}{|c|}{ Travoprost (highteens group: $n=54$ ) } \\
\hline & Mean IOP (mmHg) & Percent reduction (\%) & Mean IOP (mmHg) & Percent reduction (\%) \\
\hline & & from the baseline IOP & & from the baseline IOP \\
\hline Baseline & $16.9 \pm 1.5$ & & $16.9 \pm 1.4$ & \\
\hline 4 weeks & $14.1 \pm 2.2 * *$ & $16.3 \pm 13.0$ & $13.9 \pm 2.0 * *$ & $17.4 \pm 9.8$ \\
\hline 8 weeks & $14.2 \pm 2.0 * *$ & $|5.8 \pm| I . \mid$ & $13.7 \pm 1.9 * *$ & $18.9 \pm 8.5$ \\
\hline \multirow[t]{2}{*}{12 weeks } & $14.0 \pm 2.0 * *$ & $16.7 \pm 10.8$ & $14.2 \pm 2.2 * *$ & $16.2 \pm 10.6$ \\
\hline & \multicolumn{2}{|c|}{ Tafluprost (lowteens group: $n=33$ ) } & \multicolumn{2}{|c|}{ Travoprost (lowteens group: $n=36$ ) } \\
\hline Baseline & $13.0 \pm 1.2$ & & $13.2 \pm 1.2$ & \\
\hline 4 weeks & $11.4 \pm 1.5^{* *}$ & $12.5 \pm 11.8$ & $11.5 \pm 1.7 * *$ & $12.1 \pm 13.2$ \\
\hline 8 weeks & $11.4 \pm 1.7 * *$ & $11.6 \pm 14.2$ & $11.5 \pm 1.5 * *$ & $11.8 \pm 11.2$ \\
\hline 12 weeks & $11.7 \pm 1.9 * *$ & $10.2 \pm 13.5$ & $11.7 \pm 1.5^{* *}$ & $10.5 \pm 11.5$ \\
\hline
\end{tabular}

Notes: The patients in highteens group were defined as the baseline intraocular pressure of $\leqq 15 \mathrm{mmHg}$. The patients in lowteens group were defined as the baseline intraocular pressure of $<15 \mathrm{mmHg}$. $* * P<0.001$ vs Baseline, One-way repeated-measures analysis of variance. 
Table 4 The number of subjects who experienced a percent reduction from the baseline IOP in patients with normal tension glaucoma and subgroups

\begin{tabular}{|c|c|c|c|}
\hline \multirow{2}{*}{$\begin{array}{l}\text { Percent reduction after } 12 \text { weeks } \\
\text { in mean IOP from baseline }\end{array}$} & \multicolumn{2}{|l|}{ No of subjects (\%) } & \multirow{2}{*}{$\begin{array}{l}P \text { value } \\
\text { (Pearson } X^{2} \text { test) }\end{array}$} \\
\hline & Tafluprost $(n=90)$ & Travoprost $(n=90)$ & \\
\hline$\geqq 10 \%$ & $65(72.2)$ & $56(62.2)$ & 0.132 \\
\hline$\geqq 20 \%$ & $33(36.7)$ & $32(35.5)$ & 0.859 \\
\hline \multirow[t]{2}{*}{$\geqq 30 \%$} & $7(7.8)$ & $5(5.5)$ & 0.513 \\
\hline & $\begin{array}{l}\text { Tafluprost } \\
\text { (highteens group: } \mathbf{n}=57 \text { ) }\end{array}$ & $\begin{array}{l}\text { Travoprost } \\
\text { (highteens group: } \mathrm{n}=54 \text { ) }\end{array}$ & \\
\hline$\geqq 10 \%$ & $43(75.4)$ & $37(68.5)$ & 0.277 \\
\hline$\geqq 20 \%$ & $26(45.6)$ & $23(42.6)$ & 0.669 \\
\hline \multirow[t]{2}{*}{$\geqq 30 \%$} & $6(10.5)$ & $3(5.6)$ & 0.202 \\
\hline & $\begin{array}{l}\text { Tafluprost } \\
\text { (lowteens group: } n=33 \text { ) }\end{array}$ & $\begin{array}{l}\text { Travoprost } \\
\text { (lowteens group: } n=36 \text { ) }\end{array}$ & \\
\hline$\geqq 10 \%$ & $22(66.7)$ & $19(52.8)$ & $0.045 * *$ \\
\hline$\geqq 20 \%$ & $7(2 \mid .2)$ & $9(25.0)$ & 0.523 \\
\hline$\geqq 30 \%$ & I (3.0) & $2(5.6)$ & 0.365 \\
\hline
\end{tabular}

Notes: The patients in highteens group were defined as the baseline intraocular pressure of $\leqq I 5 \mathrm{mmHg}$. The patients in lowteens group were defined as the baseline intraocular pressure of $<15 \mathrm{mmHg}$.

Abbreviation: IOP, intraocular pressure.

considerably between PGs. There were many reports stating that the absence of any IOP-lowering effect is considered a class effect, so that the current practice is to use another therapeutic class rather than use another PG. If there are differences in the response to PGs in the same patients all PGs
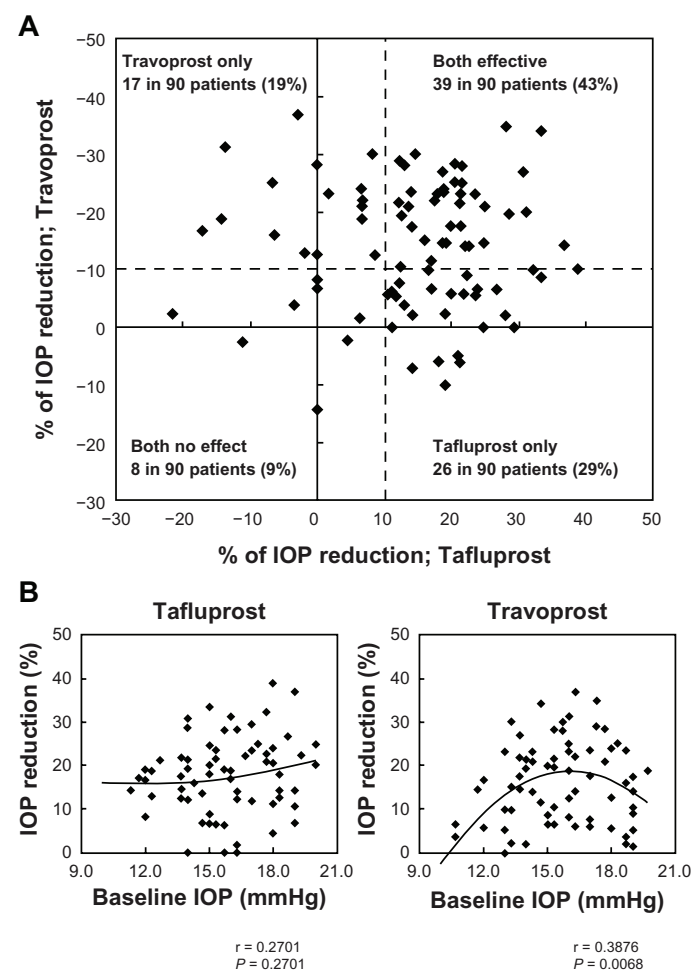

Figure I (A) The relationship between percent reductions of intraocular pressure (IOP) by tafluprost and travoprost. Dashed line represents a border of $10 \% 10 P$ reduction. (B) Polynomial regression analysis shows the relationship between baseline IOP and percent IOP reduction from baseline IOP.

Abbreviation: IOP, intraocular pressure. should be tested before declaring this class ineffective and select the most effective PGs.

We speculate that the difference to response in each prostaglandin is related to several factors, such as the difference in corneal permeability, ${ }^{21}$ intraocular drug metabolism, ${ }^{22}$ variety in the expressed FP-receptor, ${ }^{23}$ or a difference in the composition of the functional FP-receptor. ${ }^{24}$ Currently, it is difficult to predict the susceptibility to individual drugs in advance. It would be desirable to develop a screening method for identification of the optimum prostaglandin analogue for individual cases.

There are several limitations to this study. The study involved open-labeled treatment to observers. Potential limitations include the relatively short treatment periods of 12 weeks and lack of diurnal variation.

In summary, this study was designed to evaluate the efficacy and safety of tafluprost and travoprost in patients with NTG, and revealed that both drugs had a comparative effect on lowering IOP. However, the susceptibility to the two drugs differed in approximately $50 \%$ of patients with NTG. This difference must be considered when using these drugs for treating NTG.

\section{Disclosure}

This research received no specific grant from any funding agency in the public, commercial or not-for-profit sectors. All authors have no conflict of interest.

\section{References}

1. The Collaborative Normal-Tension Glaucoma Study Group. The effectiveness of intraocular pressure reduction in the treatment of normaltension glaucoma. Am J Ophthalmol. 1998;126:498-505. 
2. The Collaborative Normal-Tension Glaucoma Study Group. Comparison of glaucomatous progression between untreated patients with normaltension glaucoma and patients with therapeutically reduced intraocular pressures. Am J Ophthalmol. 1998;126:487-497.

3. Iwase A, Suzuki Y, Araie M, et al. The prevalence of primary openangle glaucoma in Japanese. Ophthalmology. 2004;111:1641-1648.

4. Rulo AH, Greve EL, Geijssen HC, Hoyng PFJ. Reduction of intraocular pressure with treatment of latanoprost once daily in patients with normal-pressure glaucoma. Ophthalmology. 1996;103:1276-1282.

5. Drance SM, Crichton A, Mills RP. Comparison of the effect of latanoprost $0.005 \%$ and timolol $0.5 \%$ on the calculated ocular perfusion pressure in patients with normal-tension glaucoma. Am J Ophthalmol. 1998;125:585-592.

6. Harris A, Migliardi R, Rechtman E, Cole CN, Yee AB, Garzozi HJ. Comparative analysis of the effects of dorzolamide and latanoprost on ocular hemodynamics in normal tension glaucoma patients. Eur $J$ Ophthalmol. 2003;13:24-31.

7. Tomita G, Araie M, Kitazawa Y, Tsukahara S. A three-year prospective, randomized and open comparison between latanoprost and timolol in Japanese normal-tension glaucoma patients. Eye. 2004;18:984-989.

8. Dirks MS, Noecker RJ, Earl M, Roh S, Silverstein SM, Williams RD. A 3-month clinical trial comparing the IOP-lowering efficacy of bimatoprost and latanoprost in patients with normal-tension glaucoma. Adv Ther. 2006;23:385-394.

9. Kiuchi T, Motoyama Y, Oshika T. Influence of ocular hypotensive eyedrops on intraocular pressure fluctuation with postural change in eyes with normal-tension glaucoma. Am J Ophthalmol. 2007;143:693-695.

10. Quaranta L, Pizzolante T, Riva I, Haidich A-B, Konstas AGP, Stewart WC. Twenty-four-hour intraocular pressure and blood pressure levels with bimatoprost versus latanoprost in patients with normal-tension glaucoma. Br J Ophthalmol. 2008;92:1227-1231.

11. Suh MH, Park KH, Kim DM. Effect of travoprost on intraocular pressure during 12 months of treatment for normal-tension glaucoma. Jpn J Ophthalmol. 2009;53:18-23.

12. Kuwayama Y, Komemusi S. Intraocular pressure lowering effect of $0.0015 \%$ tafluprost as compared to placebo in patients with normal tension glaucoma: Randomized, double-blind, multicenter. Phase III study. J Jpn Ophthalmol Soc. 2010;114:436-443.
13. Nomura Y, Nakakura S, Moriwaki M, Takahashi Y, Shiraki K. Effect of travoprost on 24-hour intraocular pressure in normal tension glaucoma. Clin Ophthalmol. 2010;30:643-647.

14. Ang GS, Kersey JP, Shepstone L, Broadway DC. The effect of travoprost on daytime intraocular pressure in normal tension glaucoma: a randomized controlled trial. Br J Ophthalmol. 2008;92:1129-1233.

15. Aung T, Chew PTK, Yip C-C, et al. A randomized double-masked crossover study comparing latanoprost $0.005 \%$ with unoprostone $0.12 \%$ in patients with primary open-angle glaucoma and ocular hypertension. Am J Ophthalmol. 2001;131:636-642.

16. Scherer WJ. A retrospective review of non-responders to latanoprost. J Ocular Pharmacol Ther. 2002;18:287-291.

17. Camras CB, Hedman K; US Latanoprost Study Group. Rate of response to latanoprost or timolol in patients with ocular hypertension or glaucoma. J Glaucoma. 2003;12:466-469.

18. Rossetti L, Gandolfi S, Traverso C, et al. An evaluation of the rate of nonresponders to latanoprost therapy. J Glaucoma. 2006;15: $238-243$.

19. Fukuda M. Classification and treatment of diabetic retinopathy. Diabetes Res Clin Pract. 1994;24 Suppl:S171-S176.

20. Cheng JW, Cai JP, Wei RL. Meta-analysis of medical intervention for normal tension glaucoma. Ophthalmology. 2009;116:1243-1249.

21. Hariharan S, Minocha M, Mishra GP, Pal D, Krishna R, Mitra AK. Interaction of ocular hypotensive agents (PGF2 alpha analogs-bimatoprost, latanoprost, and travoprost) with MDR efflux pumps on the rabbit cornea. J Ocul Pharmacol Ther. 2009;25:487-498.

22. Okita RT, Okita JR. Prostaglandin-metabolizing enzymes during pregnancy: characterization of $\mathrm{NAD}(+)$-dependent prostaglandin dehydrogenase, carbonyl reductase, and cytochrome P450-dependent prostaglandin omega-hydroxylase. Crit Rev Biochem Mol Biol. 1996;31(2):101-126.

23. Sakurai M, Higashide T, Takahashi M, Sugiyama K. Association between genetic polymorphisms of the prostaglandin $\mathrm{F} 2 \alpha$ receptor gene and response to latanoprost. Ophthalmology. 2007;114:1039-1045.

24. Liang Y, Woodward DF, Guzman VM, et al. Identification and pharmacological characterized of the prostaglandin FP receptor and FP receptor variant complexes. Br J Pharmacol. 2008;154: 1079-1093.
Clinical Ophthalmology

\section{Publish your work in this journal}

Clinical Ophthalmology is an international, peer-reviewed journal covering all subspecialties within ophthalmology. Key topics include: Optometry; Visual science; Pharmacology and drug therapy in eye diseases; Basic Sciences; Primary and Secondary eye care; Patient Safety and Quality of Care Improvements. This journal is indexed on Submit your manuscript here: http://www.dovepress.com/clinical-ophthalmology-journal

\section{Dovepress}

PubMed Central and CAS, and is the official journal of The Society of Clinical Ophthalmology (SCO). The manuscript management system is completely online and includes a very quick and fair peer-review system, which is all easy to use. Visit http://www.dovepress.com/ testimonials.php to read real quotes from published authors. 